\title{
Del Horizonte Medio al Horizonte Tardío en la costa sur central: el caso del valle de Asia
}

De l'Horizon moyen à l'Horizon récent sur la côte centrale: le cas de la vallée de Asia

From the middle horizon to the late horizon on the south central coast: the case of the asia valley

\section{Rommel Angeles Falcón y Denise Pozzi-Escot*}

\section{(2) OpenEdition \\ Journals}

\section{Edición electrónica}

URL: http://journals.openedition.org/bifea/5388

DOI: $10.4000 /$ bifea.5388

ISSN: 2076-5827

Editor

Institut Français d'Études Andines

\section{Edición impresa}

Fecha de publicación: 1 diciembre 2004

Paginación: 861-886

ISSN: 0303-7495

Referencia electrónica

Rommel Angeles Falcón y Denise Pozzi-Escot*, « Del Horizonte Medio al Horizonte Tardío en la costa sur central: el caso del valle de Asia », Bulletin de l'Institut français d'études andines [En línea], 33 (3) I 2004, Publicado el 08 diciembre 2004, consultado el 01 diciembre 2020. URL : http:// journals.openedition.org/bifea/5388; DOI : https://doi.org/10.4000/bifea.5388

Les contenus du Bulletin de l'Institut français d'études andines sont mis à disposition selon les termes de la licence Creative Commons Attribution - Pas d'Utilisation Commerciale - Pas de Modification 4.0 International. 
Bull. Inst. fr. études andines

2004, 33 (3): 861-886

\title{
DEL HORIZONTE MEDIO AL HORIZONTE TARDÍO EN LA COSTA SUR CENTRAL: EL CASO DEL VALLE DE ASIA
}

\author{
Rommel ANGELES FALCÓN*, Denise POZZI-ESCOT**
}

\section{Resumen}

El valle de Asia, situado a 100 kilómetros al sur de Lima, jugó un rol de importancia durante el Horizonte Medio. En efecto, los contextos funerarios de Huaca Malena, así como los finos textiles que los acompañan indican una fuerte relación con Wari, Pachacamac, la Costa Central y la Costa Norte. De acuerdo con la evidencia textil, el tránsito del Horizonte Medio al periodo Intermedio Tardío incrementó las relaciones con la costa central.

Para el periodo Intermedio Tardío, de acuerdo a la información etnohistórica, el valle estuvo habitado por los coayllo, quienes tributaban a Pachacamac. Durante el Horizonte Tardío, los incas construyen importantes centros administrativos en el valle, y la cerámica durante este periodo se relacionó fuertemente con los estilos propios de los vecinos valles norteños de Mala, Chilca y la costa de Lima.

Palabras claves: Asia, Huaca Malena, textiles, Coaylllo, Pachacamac.

\section{DE L'HORIZON MOYEN À L'HORIZON RÉCENT SUR LA CÔTE CENTRALE : LE CAS DE LA VALLÉE DE ASIA}

\section{Résumé}

La vallée de Asia, située à quelque $100 \mathrm{~km}$ au sud de Lima, a joué un rôle important durant l'Horizon moyen. En effet, les contextes funéraires de la Huaca Malena et les textiles élaborés qui en sont issus, suggèrent d'étroites relations avec Huari, Pachacamac, et les côtes centrale et nord. L'étude des textiles nous permet de voir que la transition de l'Horizon moyen à la période Intermédiaire récent se marque par une croissance des relations avec la côte centrale.

Selon les données ethnohistoriques, la vallée de Asia était durant la période Intermédiaire récent habitée par les Coyallo, qui versaient tribut à Pachacamac. À l'Horizon récent, les Incas construisirent d'importants centres administratifs dans la vallée, et durant cette période le

\footnotetext{
*Museo Municipal Huaca Malena, Asia. E-mail: rommelangel@ hotmail.com

** ICOM Perú. E-mail: adejai@bonus.com.pe
} 
matériel céramique montre de fortes relations avec les styles des vallées voisines au nord, comme Mala, Chilca, et la côte aux alentours de Lima.

Mots clés Asia, Huaca Malena, textiles, le Coayllo, Pachacamac.

\title{
FROM THE MIDDLE HORIZON TO THE LATE HORIZON ON THE SOUTH CENTRAL COAST: THE CASE OF THE ASIA VALLEY
}

\begin{abstract}
The Asia valley, which is situated $100 \mathrm{~km}$ south of Lima, played an important role during the Middle Horizon. In fact, the funerary contexts of the Huaca Malena, as well as the elaborate textiles that were found in them, suggest a strong relationship with Wari, Pachacamac, the central and the north coasts. From the textile evidence the transition from the Middle Horizon to the Late Intermediate Period showed an increase in relations with the central coast.

In accordance with ethnohistorical data, during the Late Intermediate Period the valley was inhabited by the Coayllo, who gave tribute to Pachacamac. During the Late Horizon the Incas built important administrative centres in the valley, and during this period the ceramic material shows a strong relationship to styles found in neighbouring valleys to the north, such as Mala, Chilca and the coast around Lima.
\end{abstract}

Key words: Asia, Huaca Malena, textiles, the Coayllo, Pachacamac.

\section{EL VALLE DE ASIA}

El valle de Asia se encuentra situado a 100 kilómetros al sur de Lima, entre los valles de Mala por el norte y Cañete por el Sur (Fig. 1). Destaca por su aridez, el amplio cono deyectivo y sus playas arenosas frente a la isla de Asia donde habitan lobos de mar, además de constituir un importante lugar para el anidamiento de aves guaneras.

Destaca la pesca artesanal, que se realiza principalmente desde las peñas. Las extensas playas arenosas son frecuentadas por aves guaneras y habitadas por moluscos y bivalvos como la "macha" (Mesodesma donacium), el "morocho" (Donax sp.); un tipo de concha (Mulinia edulis) y el crustáceo "muy-muy" (Emerita análoga). Hasta hace unos veinte años, era frecuente el uso de balsas de totora para la pesca artesanal, embarcaciones construidas con materia prima procedente de Bujama, en el vecino valle de Mala.

El valle bajo presenta una alta densidad de sitios arqueológicos correspondientes al periodo Precerámico (Engel, 1963), Inicial (Angeles, 2003) así como al Intermedio Temprano, como es el caso de Huaca Malena (Engel, 1963; 1987; Tello, 2000; Angeles \& Pozzi-Escot, 2000). Es un valle de clima árido y semicálido, sus suelos son relativamente planos y de naturaleza aluvial, coluvial y eólica, observándose en los perfiles la presencia de avenidas y huaycos que a lo largo de los años han dado forma a este territorio.

El río Asia trae agua de manera esporádica solo unos días durante el verano por lo que la agricultura es bastante difícil, utilizándose para tal efecto el agua del subsuelo 


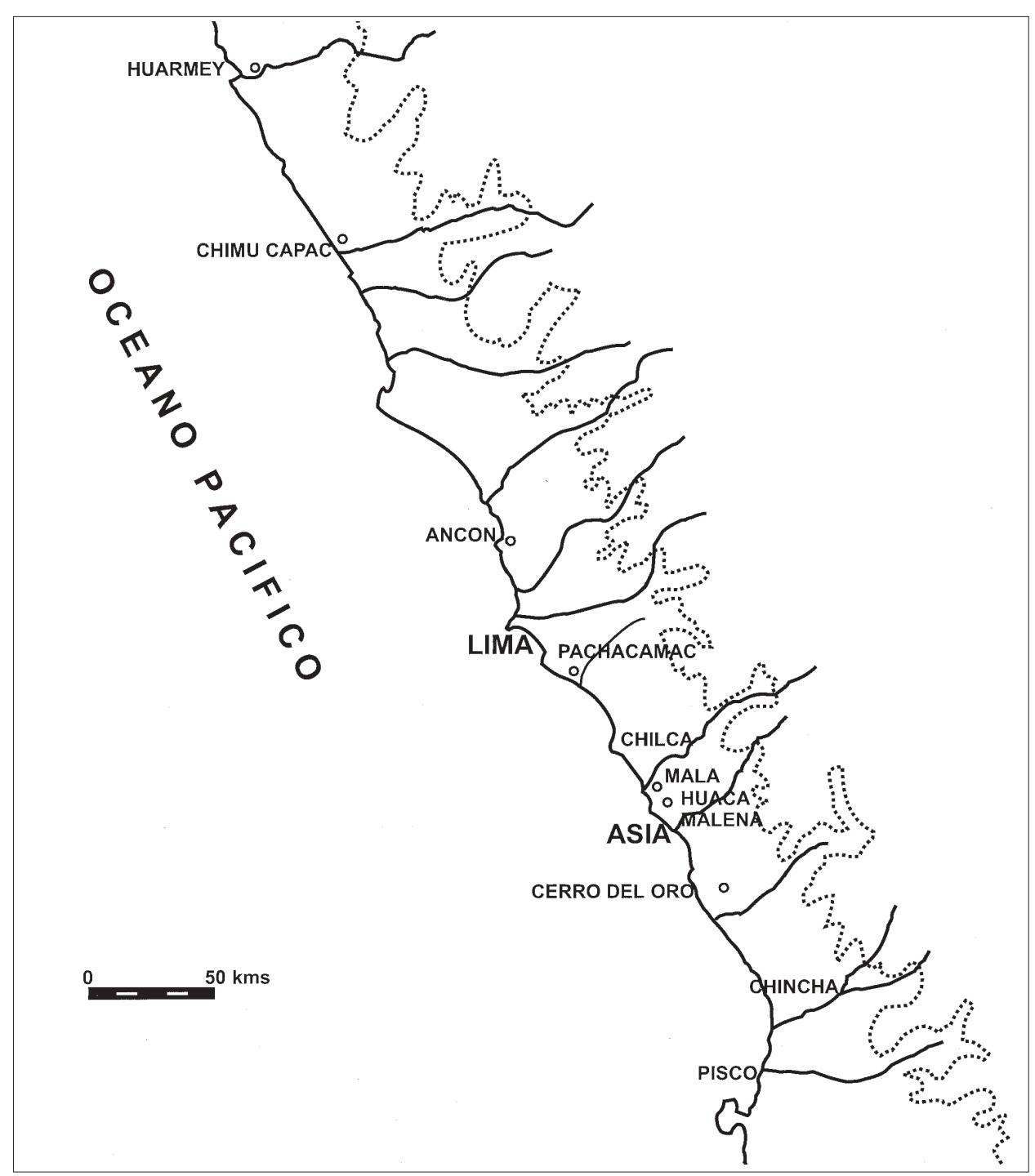

Fig. 1 - Mapa de la costa indicando los sitios mencionados en el texto. 
mediante pozos. A casi un kilómetro de la playa, el cauce del río se divide en dos ramales que se denominan El Gallo y Río Chico; al parecer esta desviación podría ser de carácter prehispánico. A la altura de la localidad de Coayllo existe un puquio de agua y de las cercanías nace un canal de irrigación para el valle, mientras otro canal irriga la porción norte del valle. Ambos se inician casi en la misma toma (Tello, 2000: 13).

Hacia arriba en el valle, el espacio de las lomas es explotado en la actualidad de manera temporal por los ganaderos de la sierra, y de manera permanente para la extracción de piedras y gravilla como material de construcción por los pobladores de la costa. La lomas se ubican en ambas márgenes del valle, destacando las de Puquio Salado, Marquesa, Casablanca, Pacay, Perico, El Huaranguito al norte; las lomas de Quilmaná y Ancapuquio al sur. La zona de lomas presenta sitios arqueológicos generalmente tardíos, siendo necesaria la realización de trabajos sistemáticos para definir mejor estas ocupaciones. En las inmediaciones de la loma Casablanca existen líneas y geoglifos que requieren ser fechados con precisión.

El valle medio es estrecho y de bordes pendientes, ensanchándose a la altura de las localidades de Coayllo, Uquira y Omas. Coayllo es el poblado principal, tiene un clima cálido y agricultura permanente. Presenta una iglesia que data del periodo colonial, el ordenamiento físico de las manzanas es de origen español pero adaptado a la estrechez del valle. Las características del clima permiten el cultivo de frutales y maíz. En la actualidad, el valle medio presenta una baja densidad poblacional a pesar de que presenta las áreas de mayor productividad. Ello contrasta con el alto número de sitios prehispánicos que indicarían quizás una mayor densidad poblacional.

El valle medio destaca por la gran cantidad de sitios correspondientes al Horizonte Medio y a los periodos tardíos, representados ya sea por aldeas o por centros administrativos (Angeles, 2003).

Frédéric Engel señala la existencia de 190 sitios (20 precerámicos, 87 Chavín, 3 Huari, 2 huacas post-huari: Huaca Malena y Huaca Partida, 26 poblados Ica-ChinchaCañete y uno con rasgos incaicos así como 50 no determinados [Engel, 1987: 165]).

\section{EL HORIZONTE MEDIO EN EL VALLE DE ASIA}

El Horizonte Medio constituyó una etapa crucial en los Andes Centrales que implicó cambios en el patrón funerario, el crecimiento de una serie de asentamientos y el desarrollo de un sistema ideológico que unificó gran parte de esta zona con sus respectivos aportes locales. El tránsito de este complejo periodo y su transformación hacia un periodo donde las sociedades adquieren una personalidad particular, de carácter local, es un fenómeno poco conocido.

La primera época del Horizonte Medio presenta un estilo cerámico particular, reconocido como Estilo Cerro del Oro (Kroeber, 1937), derivado del importante sitio del mismo nombre en el valle bajo de Cañete, donde se ubica el sitio de mayor complejidad y dimensión (Kroeber, 1937; Stumer, 1971; Ruales, 2002).

Sitios con arquitectura y cerámica de estilo Cerro del Oro son reportados también entre Chilca (Sawilka), Mala (San José del Monte, Esquivilca, Cerro Salazar [Gabe, 2000]), Asia (Quisque, Las Palmas, entre otros) y Cañete (Cerro del Oro, La Quebrada, 
Lunahuaná). Este estilo no se encuentra presente en el valle de Lurín y tampoco en Chincha y Pisco (Angeles, 2003).

Efectivamente, en los valles vecinos de Chilca, Mala y particularmente en el valle de Asia, los sitios de este periodo son generalmente de tipo habitacional, ubicándose en pequeñas quebradas o en terrazas con arquitectura de piedra y pequeños adobes cúbicos hechos a mano, no habiéndose registrado grandes complejos de uso ceremonial o administrativo. Esto hace pensar que podría tratarse de una sociedad centralizada, cuya sede principal se ubicaría en el valle de Cañete. La arquitectura asociada a los mismos, se caracteriza por estructuras de piedra a manera de plataformas sobre las cuales aparecen muros de pequeños adobes cúbicos hechos a mano (Angeles, 2003).

La Época 2 del Horizonte Medio implica un cambio radical, pero no se han reconocido sitios habitacionales con claridad; sin embargo, destacan las tumbas emplazadas sobre las estructuras de las edificaciones del Intermedio Temprano de Huaca Malena (Angeles \& Pozzi-Escot, 2000; 2002).

En 1997 realizamos excavaciones arqueológicas en Huaca Malena (Fig. 2), sitio arqueológico ubicado en el valle bajo de Asia, a 100 kilómetros al sur de Lima en el distrito de Asia, provincia de Cañete, departamento de Lima. El sitio destaca por su arquitectura de adobes hemicilíndricos, hechos a mano, que conforman una extensa plataforma artificial de 4 hectáreas sobre la cual se ubican plataformas menores a las cuales se accede por rampas. De acuerdo con la arquitectura y la cerámica, el sitio data de fines del periodo Intermedio Temprano. La parte superior de la misma fue reutilizada

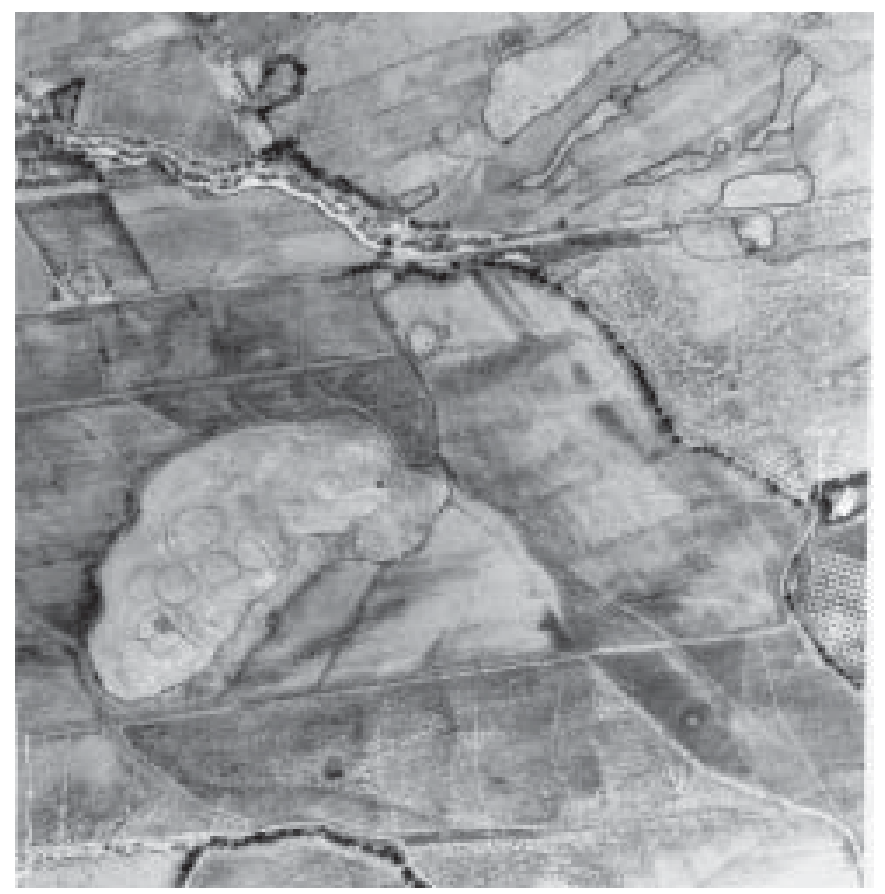

Fig. 2 - Huaca Malena en el valle bajo de Asia. 
como cementerio durante el Horizonte Medio, destacando las tumbas de la época 2 y 3 del Horizonte Medio así como algunas más tardías. El sitio se hallaba altamente depredado por el huaqueo; sin embargo, recuperamos una gran cantidad de textiles decorados y llanos correspondientes a estos periodos, así como contextos funerarios intrusivos que nos permiten aproximarnos a una interpretación diferente de la que nos proporciona la cerámica y la arquitectura (Angeles \& Pozzi-Escot, 2000).

En Huaca Malena se han reportado tumbas de élite conteniendo fardos funerarios de falsa cabeza con finos tejidos Wari, de similares características a las halladas en Pachacamac (Kaulicke, 2002) y en Ancón por Reiss \& Stübel (1896-1897). La cerámica asociada, sin embargo, es llana y ausente de decoración, a excepción de pocos ejemplares que incluyen cántaros cara-gollete y vasos con la representación simplificada del grifo de Pachacamac (Fig. 3). Los tejidos de Huaca Malena son particulares, se distinguen tapices del más puro estilo Wari, así como otros correspondientes a estilos de la costa central, la costa norte y la costa nor central, subdivididos a partir de la iconografía plasmada principalmente en los tapices.

\section{EL PATRÓN FUNERARIO}

Las tumbas de Huaca Malena son intrusivas ya que se han desmantelado muros para crear cámaras funerarias; en otros casos ocupan áreas de rellenos arquitectónicos o están adosadas a muros. Generalmente las tumbas son de planta circular, cubiertas con lajas de piedra o caliche, sobre las cuales se colocan adobes y un pequeño palo a manera de señal de tumba. Al interior de la tumba pueden situarse de uno a seis individuos; generalmente los adultos ocupan la parte inferior y sobre ellos se colocan fardos de infantes.

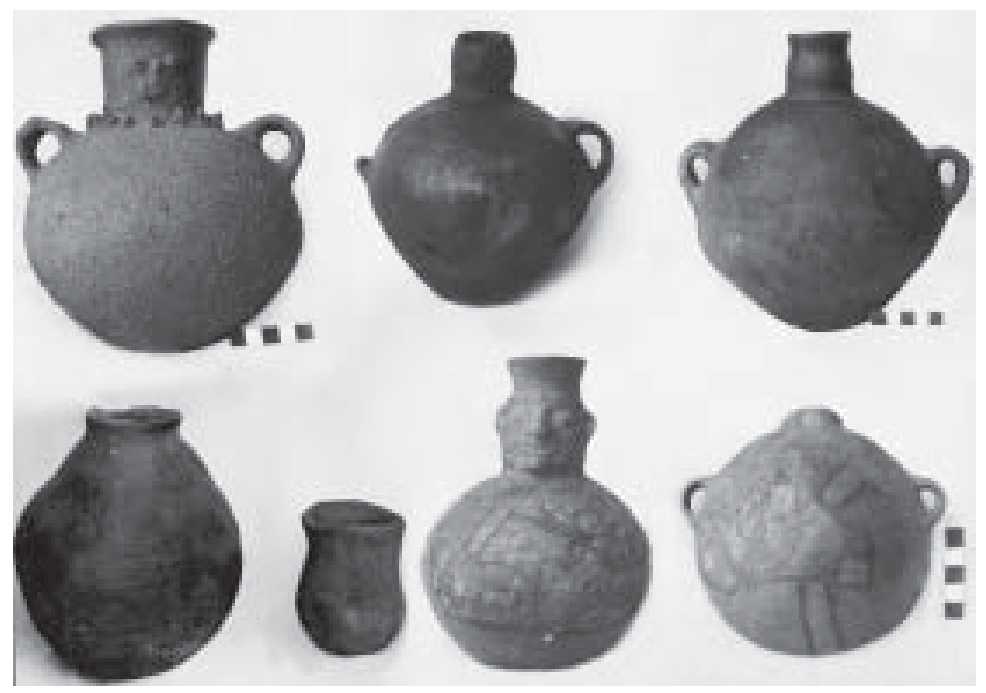

Fig. 3 - Cerámica del Horizonte Medio 2 B - 3 procedente de Huaca Malena. 
Los fardos funerarios de adultos se encuentran, en muchos casos, vestido con una camiseta o uncu; en la cabeza llevan un tocado de cestería acompañado de un penacho de plumas y una huaraca de fibra vegetal (Fig. 4). Las mujeres llevan mayormente un tejido de algodón o pelo de camélido que lo envuelve a manera de túnica sujetada a la altura del hombro por unos tupus, alfileres de metal o hilos de colores. En la cabeza llevan una vincha de pelo de camélido de trama tubular de color rojo con diseños zoomorfos.

Algunos fardos funerarios principales se caracterizan por presentar una especie de falsa cabeza que incluye ojos y lacrimales formados por láminas de metal; nariz de fibra vegetal y en algunos casos representaciones de las cejas en lana. Estos se hallan igualmente vestidos por finos tejidos.

\section{LOS TEJIDOS DE HUACA MALENA}

Las excavaciones nos permitieron recuperar aproximadamente $4 \quad 000$ textiles en contextos funerarios primarios y una gran parte procedente de la primera capa disturbada por el huaqueo y el saqueo de las tumbas.

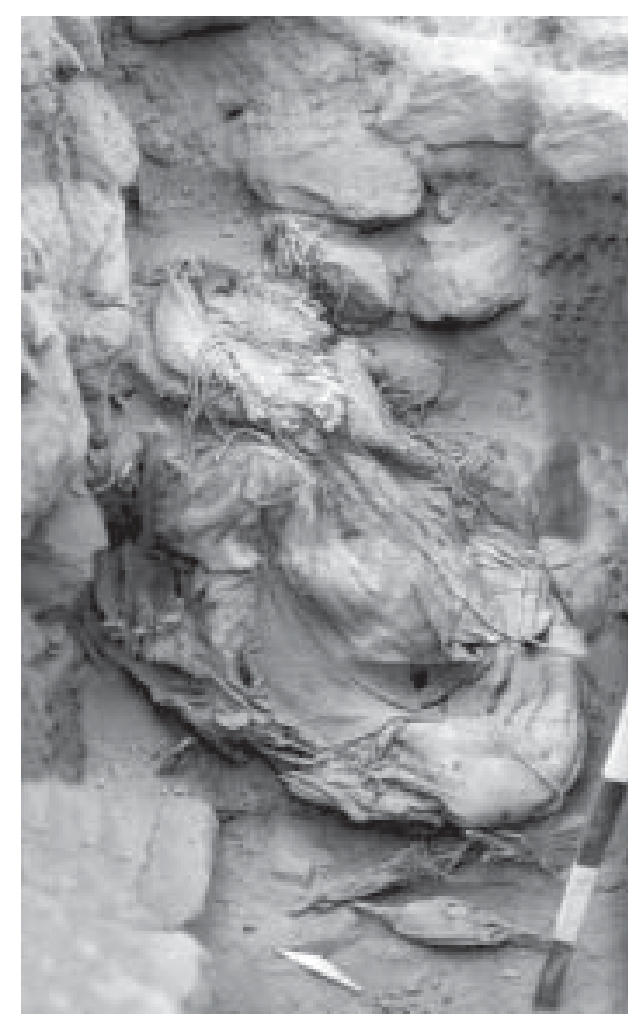

Fig. 4 - Fardo funerario de adulto vestido. Posee vincha de fibra vegetal y penacho de plumas: Sector 1, Muro 8 (Horizonte Medio, Época 2B - 3). 
La materia prima para la confección de los tejidos de Huaca Malena son el algodón y el pelo de camélido. Los tejidos de algodón se presentan en colores naturales (crudo, blanco, pardo y marrón) y, en algunos casos, teñidos en azul o naranja. Hay paños que sirvieron como envoltorio de fardos funerarios, para confeccionar miniaturas de prendas masculinas y femeninas que son colocadas en la parte externa de fardos funerarios; o para confeccionar tejidos cara de urdimbre en la técnica de paneles, así como para prendas femeninas en gasa y uncus cortos de uno o dos colores. Hay un uncu de mangas que recuerda a los reportados en Huaca Cao Viejo en La Libertad (Oakland \& Fernández, 2000: Fig. 27).

Existe una gran cantidad de paños de algodón con tapiz en medallón. Del mismo modo hay tejidos en técnica doble tela con acentos coloreados, creados por una trama suplementaria de lana de color dispuesta sobre flotantes de urdimbre, técnica reportada en materiales del Horizonte Medio en Huarmey y Pacatnamú (Conklin, 1978).

La lana, o pelo de camélido, fue utilizada de manera intensa; técnicas de cara de urdimbre en sus variedades son comunes en el material de Huaca Malena. Del mismo modo, el algodón fue utilizado en la urdimbre de tapices en sus diversas variedades.

El junco sirvió para la confección de vinchas de cestería asociadas a personas de sexo masculino; se acompañan por penachos de plumas y una honda o huaraca de fibra vegetal. Las vinchas poseen la apariencia de sombreros sin alas, en varios casos se hallan superpuestas una sobre otra, destacando su gran flexibilidad. Ejemplares similares han sido reportados en Huaca Cao Viejo (Oakland \& Fernández, 2000) así como en el Castillo de Huarmey (Prumers, 2002) y en Ancón (Kaulicke, 1997: Figs. 32 y 33 ).

Por último, los filamentos de agave fueron utilizados para la confección de los penachos de plumas. El hallazgo de algunos manojos de estas fibras nos indica que estas artesanías fueron confeccionadas localmente.

Los tapices Wari destacan en la variedad de tapiz excéntrico con urdimbres de algodón y trama de pelo de camélido, que se presenta en uncus o camisetas (Angeles \& Pozzi-Escot, 2002: Fig. 12). También se encuentran unas peculiares bandas rectangulares con apéndices, que culminan en cordoncillos confeccionados en tapiz excéntrico muy fino, con representaciones de personajes Wari en posición de perfil (Angeles \& PozziEscot, 2002: Figs. 14, 15, 16 y 17). Se trata de bandas en técnica de tapiz excéntrico con urdimbre de algodón y trama de pelo de camélido policromo, con diseños estilizados de felinos alados, personajes en posición de perfil, el grifo de Pachacamac o diseños relacionados a Wari (Fig. 5), siempre sobre fondo rojo y diseños contrapuestos. De acuerdo con Ann Rowe (com. per.) se tratarían de piezas en estilo Wari Provincial.

También se encuentran presentes tapices relacionados a Sicán o Lambayeque (Angeles \& Pozzi-Escot, 2002: Figs. 8 y 20). Este dato es importante toda vez que los reportes previos indican la presencia de finos tejidos de este estilo en Ancón y en Pachacamac (Kaulicke, 2002: Figs. 37 y 38). Los tejidos Sicán de Huaca Malena corresponden a bandas de tapiz excéntrico y ranurado, en las cuales predominan los diseños en paneles rectangulares con personajes antropomorfos de rasgos ornitomorfos en posición de perfil (Fig. 6). Diseños de aves y peces también son comunes.

Los tejidos en técnica cara de urdimbre en pelo de camélido son muy recurrentes en el material de Huaca Malena; estos incluyen tejidos de urdimbres discontinuas, 


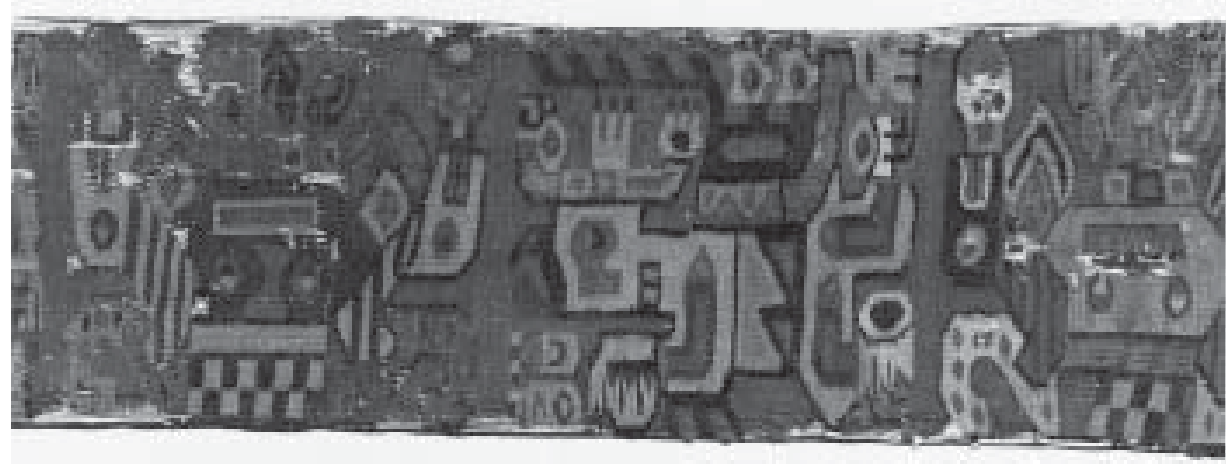

Fig. 5 - Detalle de tejido Wari con el grifo de Pachacamac. Corresponde a una banda de tapiz excéntrico. Procede del Sector I de Huaca Malena.

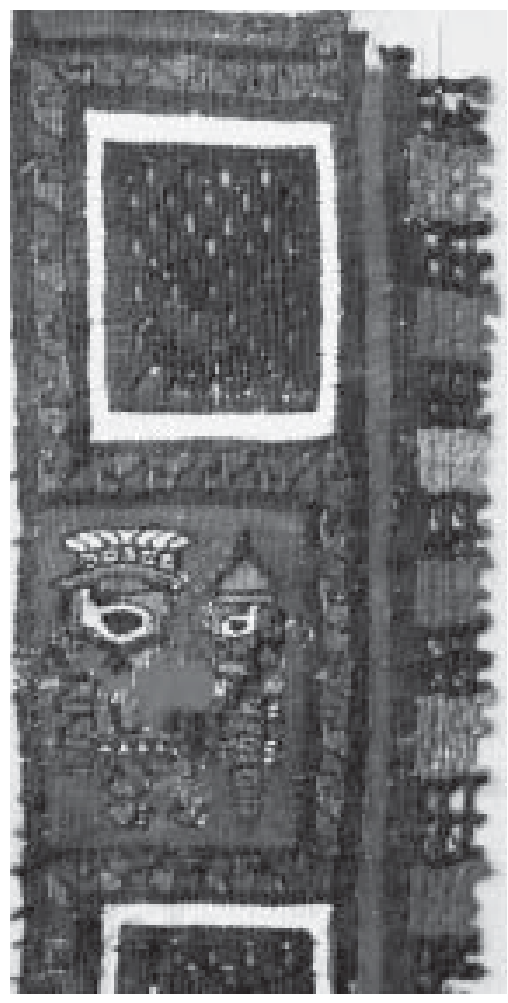

Fig. 6 - Detalle de banda en técnica tapiz, estilo Sicán o Lambayeque, procedente del sector III de Huaca Malena (Horizonte Medio, Época 3-4). 
principalmente para la confección de uncus o camisetas anchas. La trama de color marrón y la urdimbre presenta colores rojo, amarillo, verde, rosado, marrón, lila y negro. Los diseños son escalonados y aserrados, en algunos casos se incluyen paneles con diseños de felinos.

Grandes mantas de lana en técnica cara de urdimbre de urdimbres complementarias, se asocian a contextos funerarios femeninos (Fig. 7). Se trata de prendas conformadas por dos piezas, una de ellas posee decoración en paneles distribuidos en bandas paralelas destacando los tonos rojo, amarillo, marrón, ocre y rosado. Los motivos son zoomorfos (sapos y serpientes bicéfalas) y geométricos (rombos y rectángulos) para separar los paneles.

En la misma técnica han sido confeccionadas bolsas con asas laterales y boca con pasadores y ojales (Fig. 8). Los diseños incluyen un personaje estilizado de cabeza triangular, cuerpo hexagonal y miembros flexionados. Al interior de este personaje aparece un diseño zoomorfo. Adicionalmente, son comunes los diseños zoomorfos en posición de perfil, con el lomo encorvado y colmillos en la boca, entre otros diseños que incluyen diseños derivados de Wari.

La Doble Tela es una técnica que está presente en el material de Huaca Malena. Se trata de paños rectangulares de $96 \mathrm{~cm}$ de altura por $89 \mathrm{~cm}$ de ancho central. Los

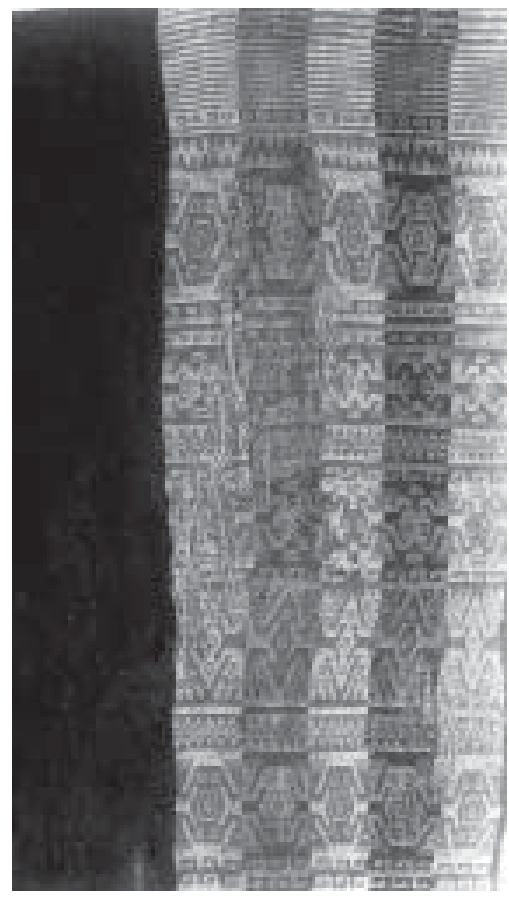

Fig. 7 - Detalle de manta en técnica cara de urdimbre de urdimbres complementarias. Procede del sector I de Huaca Malena (probablemente Horizonte Medio). 


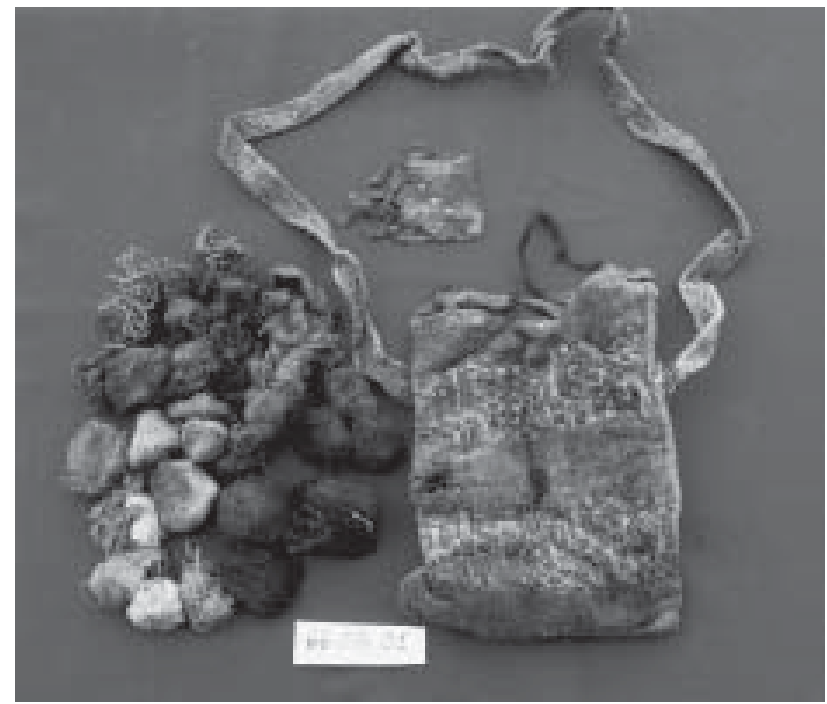

Fig. 8 - Bolsa en técnica cara de urdimbre, probable confección serrana, procedente de Huaca Malena (Periodo Horizonte Medio).

diseños más comunes corresponden a serpientes bicéfalas, predominando el color rojo a los que incluyen acentos coloreados creados por una trama suplementaria de lana de color dispuesta sobre flotantes de urdimbre (Fig. 9). Se presentan del mismo modo a manera de cintas con diseños geométricos simples. Piezas con esta técnica han sido reportadas en Pacatnamú, Huaca del Sol y Huarmey (Conklin, 1978: 306-307), así como en Ancón (Kaulicke, 1997: Figs. 35, 47 y 48), asociadas al Horizonte Medio. Sin embargo, difieren en la forma e iconografía con relación a las reportadas en Huaca Malena.

Vinchas de lana policroma, en técnica doble tela y doble cara con trama tubular cuyo anverso presenta tejido cara de urdimbre de urdimbres complementarias y el reverso posee tejido cara de urdimbre, son relativamente comunes en Huaca Malena (Fig. 10). La cara externa, por lo general, posee diseños zoomorfos, aves y serpientes geometrizadas, dentadas y entrelazadas y la cara interna presenta motivos geométricos escalonados. Estas se asocian a contextos funerarios femeninos.

\section{HUACA MALENA Y SU RELACIÓN CON LA COSTA CENTRAL}

El sitio epónimo por excelencia de la costa central es Pachacamac, uno de los principales asentamientos prehispánicos de la costa, centro de culto y peregrinaje con funciones económicas, políticas y religiosas, probablemente a partir de los desarrollos regionales, que cobró un auge especial durante el Horizonte Medio y cuya influencia creció durante los Estados y Señoríos Tardíos hasta la transformación que ejercieron los incas en el lugar. 


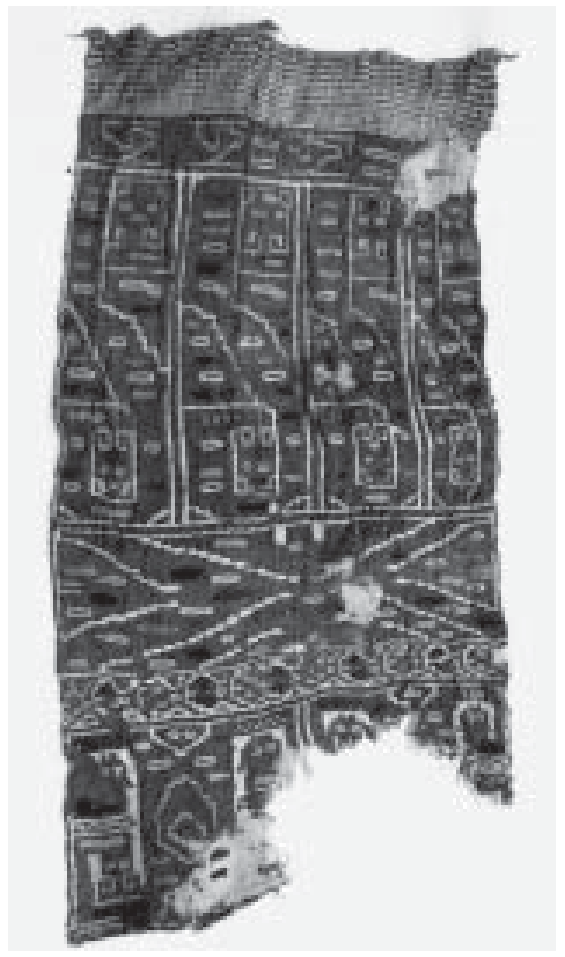

Fig. 9 - Tejido en técnica doble tela de algodón y pelo de camélido (Periodo Horizonte Medio).

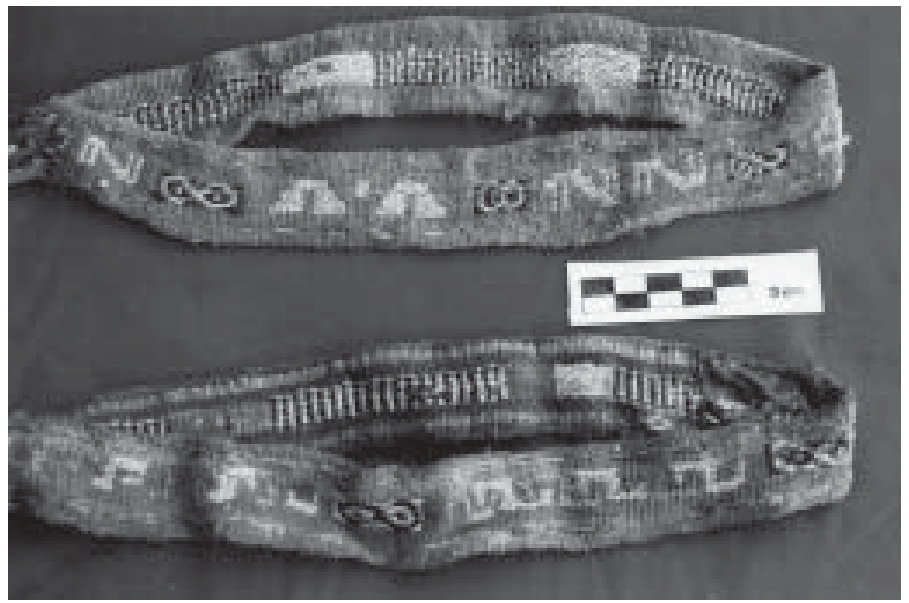

Fig. 10 - Vinchas en pelo de camélido, de uso femenino (Periodo Horizonte Medio). 
Son los textiles procedentes de los contextos funerarios del Horizonte Medio que permiten establecer una relación entre Pachacamac y Huaca Malena.

Las excavaciones de Max Uhle en Pachacamac permitieron recuperar una serie de fardos funerarios (Kaulicke, 2002: Figs. 2, 4, 5 y 6) con rasgos similares a los recuperados en Huaca Malena, principalmente en lo referente al tocado y la vestimenta de una camiseta de tapiz y plumas (Kaulicke, 2002: Figs. 1, 2, 3, 4, 5 y 6). De Pachacamac igualmente proceden tejidos de estilo Lambayeque (Kaulicke, 2002: Figs. 37 y 38) con similares características a los hallados en Huaca Malena.

Max Uhle (1903) publicó una serie de tejidos del Horizonte Medio, bajo la denominación "Periodo Epigonal", procedentes del cementerio Wari; éstos comparten similitudes con los de Huaca Malena. Citaremos el caso de las bolsas rectangulares en técnica cara de urdimbre de urdimbres complementarias (Fig. 11), tapices ranurados con la representación de cabezas de peces raya y otros diseños estilizados ilustrados por Vanstan (1967: Figs. 27, 28, 52, 55 y 70) son similares a los de Huaca Malena, lo cual insinuaría una fuerte relación entre los entierros de Pachacamac y aquellos de Huaca Malena.

En el material recuperado por Uhle en Pachacamac, se incluyen tejidos en miniatura que tienen forma de túnicas y de uncus cuadrangulares, así como bolsas alargadas conteniendo semillas (Vanstan, 1967: Figs. 1, 2, 3 y 4), relativamente comunes en los contextos de Huaca Malena y colocados en la parte media superior de los fardos funerarios. Asimismo, los uncus cortos y anchos son característicos, confeccionados en algodón o en pelo de camélido generalmente mediante la técnica de cara de urdimbre (Vanstan, 1967: Figs. 16, 17 y 18).

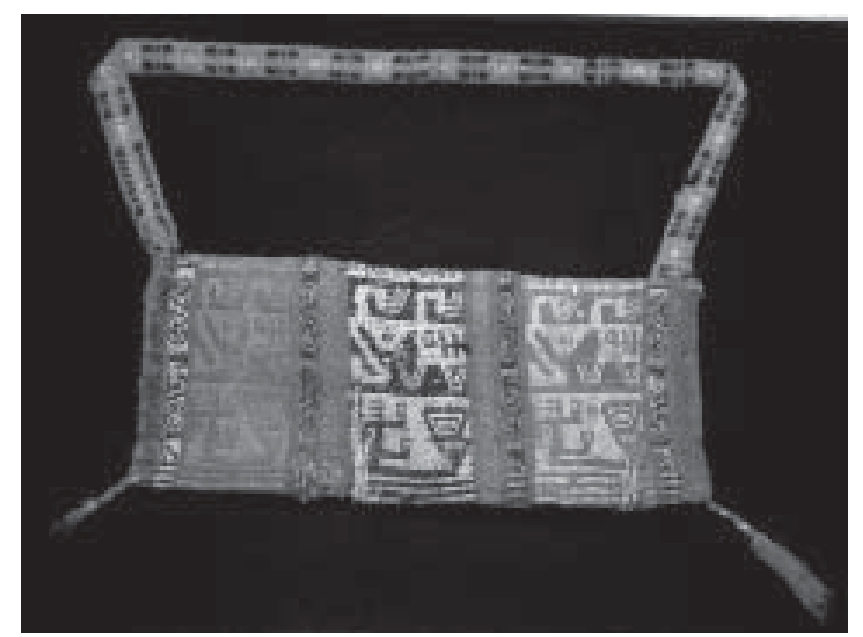

Fig. 11 - Bolsa rectangular con borlas en técnica cara de urdimbre de urdimbres complementarias. Predomina el color rojo y los diseños son zoomorfos y geométricos (Horizonte Medio). 


\section{EL PERIODO INTERMEDIO TARDÍO}

El tránsito del Horizonte Medio al periodo Intermedio Tardío - así como el mismo periodo Intermedio Tardío - es poco conocido en la costa sur central. La secuencia cultural más destacada procede de Puerto Viejo, al norte del valle de Mala, donde Duccio Bonavia (1959) definió el estilo del mismo nombre el cual aún no ha sido corroborado estratigráficamente mediante excavaciones. A pesar de la gran cantidad de sitios arqueológicos reportados en el valle de Mala (Gabe, 2000: 9) y Cañete (Stumer, 1971), no se han realizado excavaciones o levantamientos planimétricos de las estructuras correspondientes a este periodo. Del mismo modo, la información para el valle de Asia es escueta y necesita ser ampliada y sistematizada.

Un grupo de fardos funerarios de Huaca Malena pertenece a las primeras fases de este periodo; se trata de fardos de forma ovalada con envoltura de algodón llano al exterior, sujetada con soguillas de fibra vegetal que presentan tapices ranurados que recuerdan a iconos interlocking de serpientes geometrizadas entrelazadas (Fig. 12). Los fardos no se encuentran vestidos exteriormente. Algunos presentan en la cabeza una bolsa de lana beige y marrón similar a materiales procedentes de Ancón.

Se han reportado tejidos a manera de bandas, de aproximadamente $70 \mathrm{~cm}$ de ancho y $20 \mathrm{~cm}$ de altura, confeccionadas en tapiz ranurado, con iconografía relacionada al estilo interlocking de la costa central (Angeles \& Pozzi-Escot, 2002: Fig. 22). Estos presentan diseños diagonales de serpientes aserradas entrelazadas y delineadas en negro.

Del mismo modo, se aprecian tejidos en cara de urdimbre que incluyen diseños de aves estilizadas que recuerdan a los materiales reportados por Max Uhle en Ica (Rowe, 1979: Fig. 7).

Textiles recuperados de la Pirámide con Rampa n 3 de Pachacamac, han sido publicados por Jane Felthan (2000); ellos corresponden al periodo Intermedio Tardío pero no guardan relación con los tejidos de Huaca Malena.

Con relación a la cerámica del valle de Asia, esta es llana y de color marrón, mayormente en cántaros de asas laterales y ollas de cuello corto expandido. Algunas

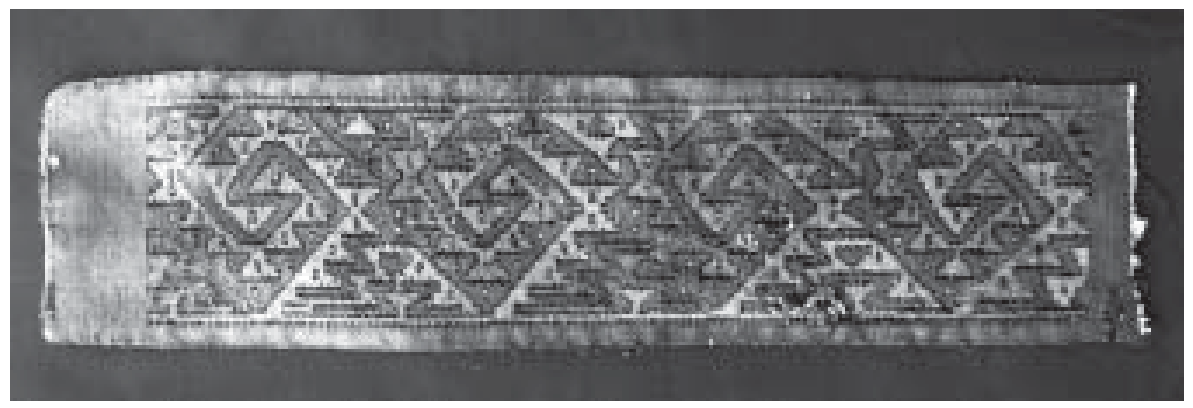

Fig. 12 - Tapiz ranurado interlocking con diseños derivados de Lima (probable inicios del Intermedio Tardío). 
vasijas que poseen decoración tricolor (Fig. 13), se encontraron en los sitios habitacionales o administrativos del valle medio.

En este período, el valle medio se caracteriza por el desarrollo de grandes asentamientos administrativos y aldeanos que se ubican principalmente en las inmediaciones del actual pueblo de Coayllo (Fig. 14). Se trata de poblados con arquitectura de piedra y barro conformando recintos rectangulares. Algunos sitios incluyen plataformas que poseen grandes vasijas incrustadas en patios interiores o sobre las plataformas. Los sitios más destacados de este periodo son Sequilao, Corralón, Coayllo y La Yesera, así como una serie de poblados ubicados en Coayllo. La arquitectura presenta muros de piedras angulosas con cantos rodados de mediano y gran tamaño unidos con argamasa de barro, y adobes irregulares que se encuentran encima de esta base (Fig. 15), que poseen un enlucido de barro muy tenue. Estos muros llegan a medir hasta dos metros de altura. La parte superior posee piedras pequeñas. La arquitectura se adapta perfectamente a la topografía abrupta del terreno.

Algunos grandes asentamientos se ubican a la entrada de grandes quebradas laterales que sirven de vía de comunicación directa con los valles vecinos.

Los sitios tardíos comprenden asentamientos aglutinados a manera de aldeas, estructuras aisladas y centros administrativos pequeños con una fuerte reocupación Inca. En el valle bajo destaca El Pacae, que constituye una aldea; asimismo, existe un sitio habitacional a la altura del cementerio moderno de Asia, donde se observa una gran cantidad de coprolitos de cuy (Cavia sp.) así como artefactos de hueso que sirvieron probablemente para desgranar maíz.

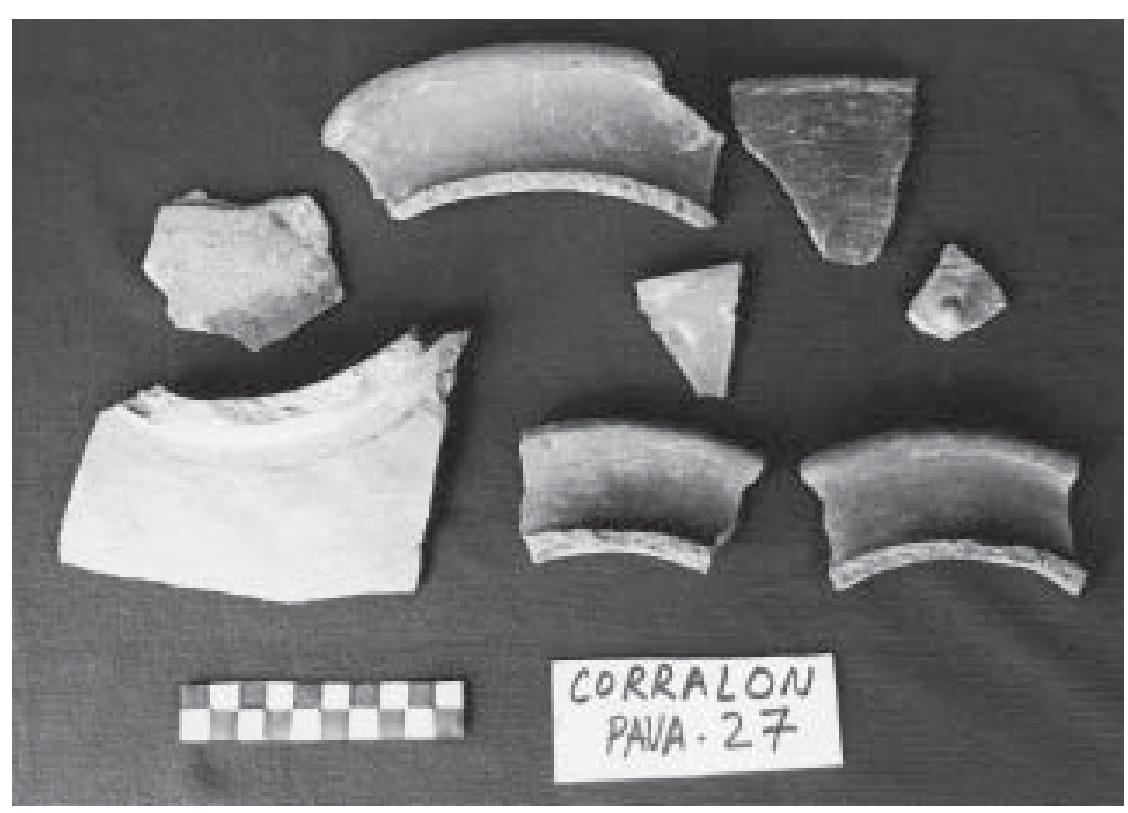

Fig. 13 - Cerámica tardía de Coayllo. 


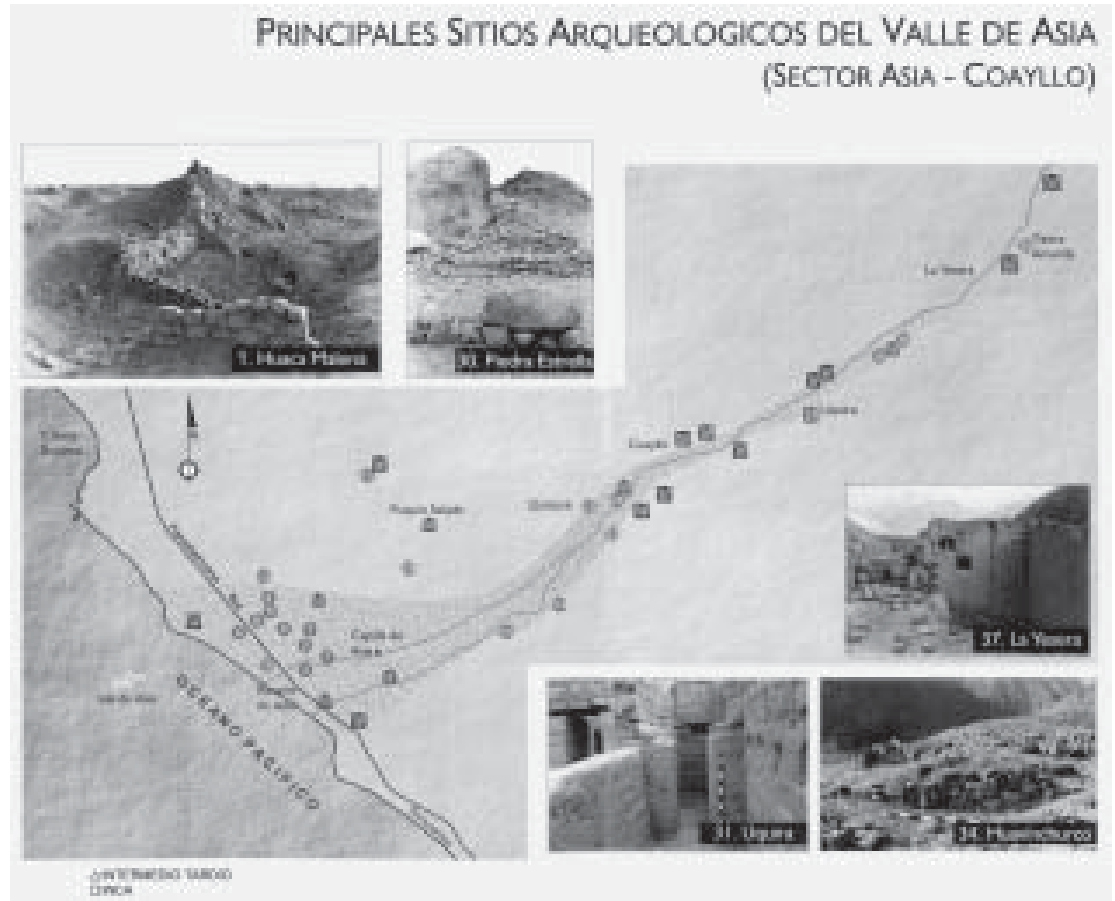

Fig. 14 - Mapa de sitios tardíos en el valle de Asia.

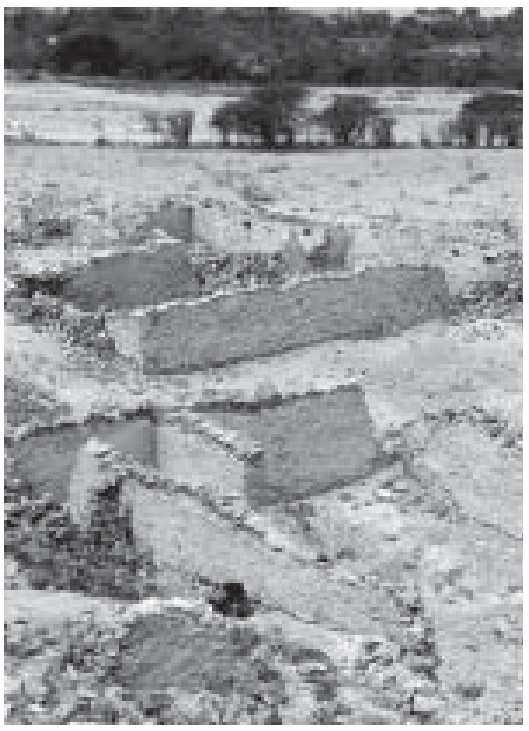

Fig. 15 - Detalle de la arquitectura tardía del valle de Asia, sector Coayllo. 
Resulta característico también el uso de huesos de mamíferos incrustados en los muros de algunos recintos. Este detalle es igualmente común en sitios tardíos de los valles de Mala y Cañete, principalmente en el valle medio. Finalmente, es característico en la arquitectura Coayllo la presencia de grandes vasijas llanas incrustadas en patios y recintos, que al parecer servían para almacenaje y se corresponden con un patrón recurrente entre los valles de Mala y Cañete, de acuerdo a observaciones efectuadas en dichas zonas.

Según María Rostworowski (1980), los Coayllo fueron el grupo étnico que habitaba el valle a la llegada de los incas; habrían estado relacionados a los yauyos quienes al parecer establecieron buenas relaciones diplomáticas con los incas, quienes les dieron tierras en Cañete luego de la derrota de los Huarco. Efectivamente, los sitios ubicados en Coayllo incluyen, en algunos casos, la presencia de cámaras funerarias rectangulares similares a las que se hallan en la localidad de Omas.

Los coayllo eran naturales del valle de Asia y habitaban la chaupiyunga de la cuenca del río Asia u Omas. Cuando se creó la Villa de Cañete, una amplia zona en el contorno de lo que es hoy San Luis, estaba habitada por indígenas de Coayllo.

De acuerdo con María Rostworowski, el valle de Asia originalmente era denominado Oclla u Ocsa, siendo unos de sus últimos curacas don Juan Coyllo, cacique del valle de Oclla y don Francisco de Ocsa. Otras maneras de referirse a Coayllo fueron Cosillo, Oquilla, Socsa u Ocsa (1980: 166).

Estete (1968) indicaba en 1535, que los señores curacas de los valles de Huarco, Mala y Socsa tributaban a la "mezquita" (Pachacamac); por ello se considera que Socsa debe corresponder al valle de Asia.

De acuerdo con Antonio Coello (1998), los Coayllo se extendieron por el este desde La Muralla (sitio arqueológico que se encuentra ubicado en Esquina de Omas, provincia de Yauyos) hasta el litoral por el oeste, ocupando el valle bajo y medio del río Asia. Por el sur se encontraban limitando con los guarco y por el norte con los calango y los mala.

Podemos destacar al sitio arqueológico de Sequilao, que presenta una ocupación del Intermedio Tardío y Horizonte Tardío. Incluye arquitectura rural de barro y piedras, un cementerio del Intermedio Tardío y una estructura a manera de plataforma del periodo Inca con grandes adobes cuadrangulares hechos con molde (Fig. 16).

El sitio La Yesera, ubicado en el anexo del mismo nombre en el distrito de Coayllo, ocupa aproximadamente 8 hectáreas que incluyen dos estructuras Inca, un cementerio de la misma época y una serie de estructuras del periodo Intermedio Tardío, además de sectores con ocupación del Intermedio Temprano. Las estructuras tardías locales incluyen batanes. Parte del sitio fue arrasado por un fuerte huayco (Fig. 17).

El sitio de Corralón, por su parte, corresponde a un extenso sitio habitacional y administrativo con ocupación en la ladera del cerro. Los incas ubicaron dos estructuras probablemente de control en la boca de la quebrada. Otros sitios destacados son Piedra Hueca y Uquira 2. 


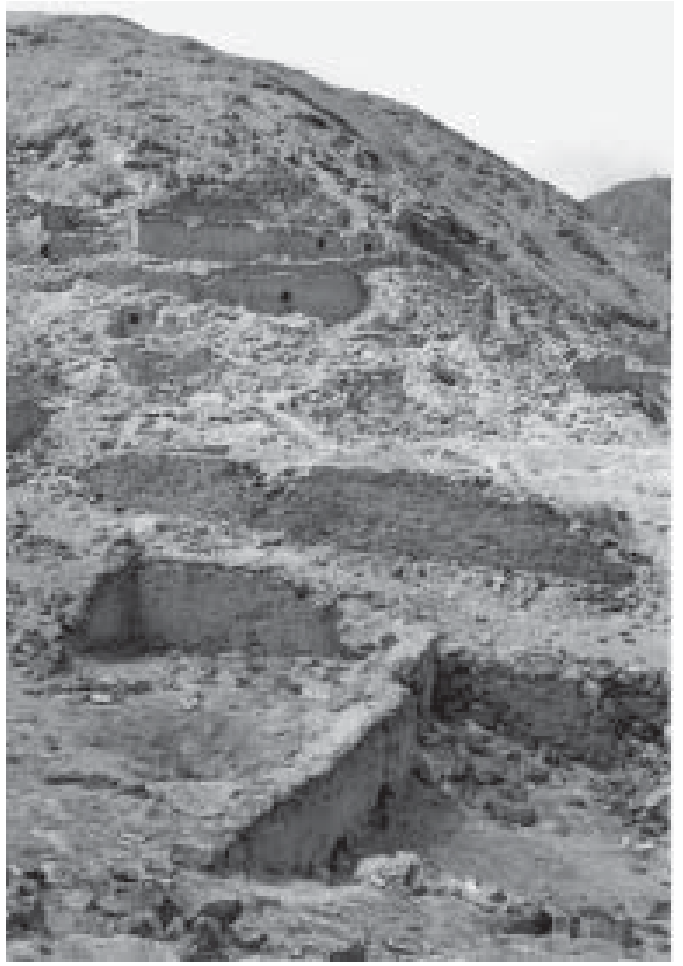

Fig. 16 - Vista de Sequilao, sitio con ocupacióndel Intermedio Tardío al Horizonte Tardío.

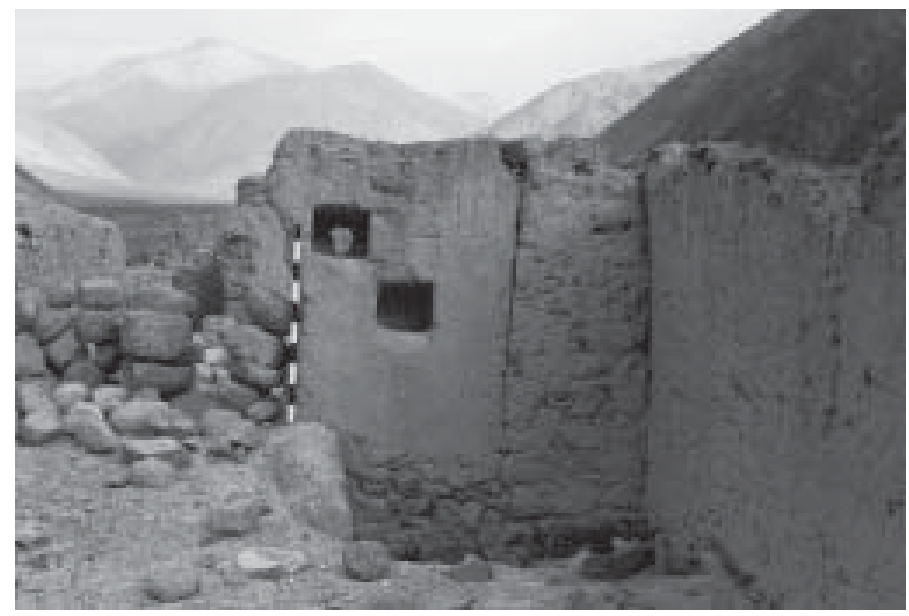

Fig. 17 - La Yesera, vista del sector Intermedio Tardío con reocupación Inca. 


\section{EL HORIZONTE TARDÍO}

A inicios del s. XV aproximadamente, los incas inician una serie de conquistas entre las que se incluyen el dominio de los valles de Mala, Asia y Cañete. En Mala, los sitios más representativos son La Vuelta, que incluye un gran asentamiento y un edificio de carácter religioso con entradas de doble jamba y pintura roja en las paredes de claro estilo Inca; Salitre, que se caracteriza por ser un extenso sitio habitacional con cementerios. En la cima del cerro se ubica un edificio de planta rectangular con hornacinas Inca; probablemente se trata del Uscovilca o centro ceremonial principal. En el valle de Asia destacan Paredones, Corralón y Uquira, además de Pueblo Viejo, en Omas. En el valle de Cañete destacan Huarco en el litoral de Cerro Azul, Incahuasi en Lunahuaná y Huacones en San Luis.

La ocupación Inca en el valle es relativamente fuerte tomando en cuenta la estrechez del mismo y su baja producción agraria. Sin embargo, al igual que en otros valles de la costa, los incas imponen una red de caminos que permite unir sus principales asentamientos desde el litoral hasta el valle alto.

Paredones — conocido igualmente como El Tambo de Asia — en el valle bajo de Asia, constituye un extraño complejo donde destaca la presencia de cuatro muros paralelos construidos en diferentes momentos que se inician detrás de unas edificaciones piramidales de tapia y concluyen tras más de un kilómetro de recorrido en una pequeña loma.

Corralón es un gran asentamiento con dos componentes, tanto del Intermedio Tardío como Inca. Del lugar proceden tejidos del periodo Inca y cerámica Inca local. Los tejidos son fajas de telar en pelo de camélido, sumamente toscas con decoración de chevrones en los bordes, predominando el color negro y los tonos amarillo y rojo, con terminales de caña en ambos extremos de urdimbre y completamente diferentes al material de Huaca Malena.

Sequilao 3 o Coayllo es un extenso sitio habitacional y administrativo con estructura Inca.

Uquira es el emplazamiento Inca más destacado del valle; posee planeamiento Inca característico aunque con rasgos propios de la costa, recordando a Tambo Colorado en el valle de Pisco. El sitio se caracteriza por estar ubicado sobre una gran plataforma artificial en la boca de una pequeña quebrada a la cual se accedía a través de una rampa. Se conservan dos sectores diferenciados y parte de un camino que se dirige hacia la parte alta del valle (Fig. 18).

Uquira incluye una plaza con pequeñas rampas laterales de acceso. La decoración de los muros recurre al uso de adobes colocados de manera alternada o escalonada para formar diseños escalonados o de cruces. Algunas hornacinas son trapezoidales pero la mayoría de ellas son rectangulares y similares a las existentes en Sequilao en el valle de Asia e Incahuasi en Cañete.

Tanto Sequilao 3 como Uquira poseen lugares de control o miradores en la parte media de los cerros.

La intención de control del valle queda evidenciada por la fuerte reocupación Inca de los sitios Coayllo, en especial los relacionados a las zonas de mayor producción agrícola y la boca de las quebradas laterales que los une con los valles de Mala y Cañete. 


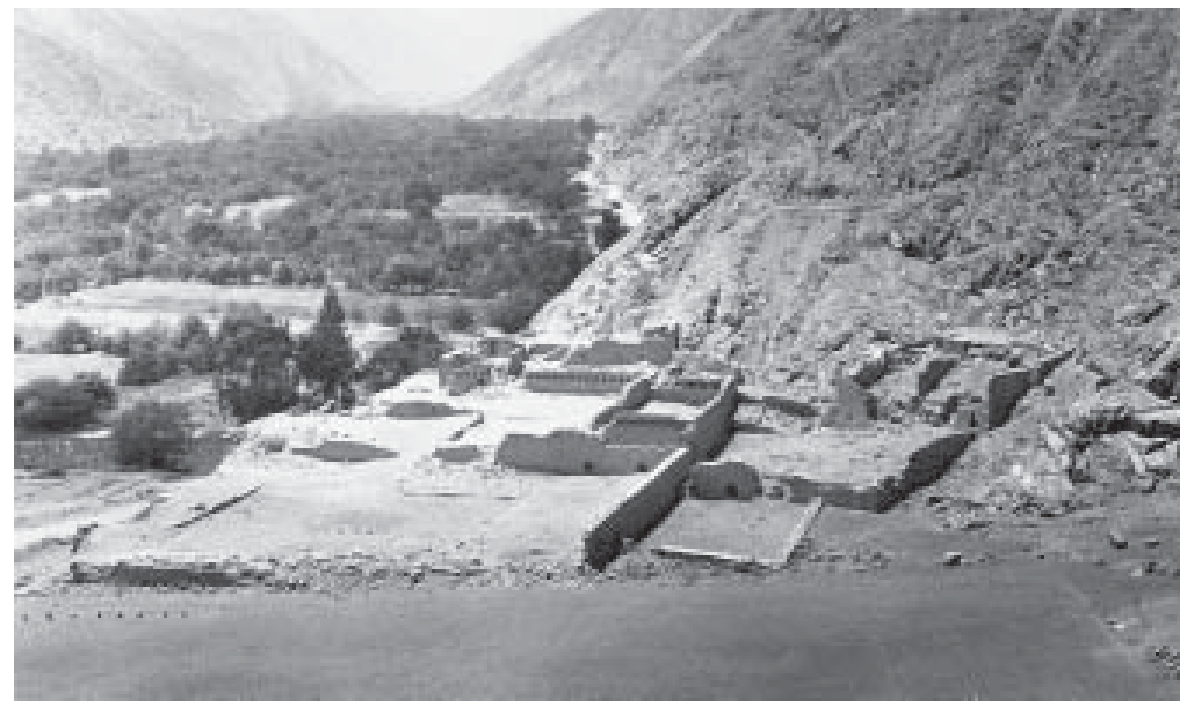

Fig. 18 - Uquira, sitio administrativo Inca en la localidad de Coayllo (Horizonte Tardío).

Sitios con ocupación Inca del valle se sitúan principalmente en la margen izquierda del río Asia u Omas en el eje del importante sitio de Uquira. Un camino de penetración a la sierra, del cual sobreviven algunos tramos, indica la importancia del valle como vía de penetración.

En el valle alto destaca el extenso sitio Inca de Pueblo Viejo, en cuyas inmediaciones se encuentra ubicada la reducción española de Omas.

Si bien algunas edificaciones tardías como Uquira y Sequilaoincluyen elementos arquitectónicos como rampas, estas son secundarias y no corresponden al eje principal de la edificación. Por lo expuesto, al menos en el valle de Asia no están presentes las pirámides con rampa tal como sucede en la costa central.

\section{LA CERÁMICA}

A partir de las observaciones de superficie podemos indicar que la cerámica del periodo Inca incluye la tradición previa de vasijas llanas en pasta naranja y marrón así como el desarrollo del estilo Puerto Viejo tricolor. Ciertamente el material observado corresponde a las mismas formas y pastas de la cerámica descrita por Bonavia y que son abundantes en el valle de Mala.

La cerámica Puerto Viejo se distribuye desde el litoral (cementerios ubicados frente a la playa), hasta las localidades de Esquina de Omas, es decir, llega hasta 30 kilómetros en el valle. Ésta incluye dos tipos de pastas principales, una de grano y alisado fino con decoración tricolor, que incluye cantaros cara gollete con asas laterales y cántaros de cuello expandido, con diseños de peces estilizados y diseños geométricos; se ha observado también fragmentos de vasijas escultóricas y de figurinas. Las vasijas 
llanas corresponden a cántaros de forma ovoide y base pequeña, presentan un acabado alisado y restregado, y la pasta contiene bastante arena. Asociado a este se reporta una cerámica llana color naranja donde predominan los cántaros de cuerpo globular, asas laterales y cuello expandido.

Materiales procedentes de dos contextos funerarios del litoral nos permiten comprender mejor la cerámica tardía de Asia. El primero de ellos corresponde al sector denominado Playa Bonita, donde durante la construcción del sótano de una vivienda se registró un contexto funerario a $70 \mathrm{cms}$ de profundidad, en mal estado de conservación. El cuerpo descansaba echado sobre la arena, en posición flexionada, poseía restos de un tejido de fibra vegetal que le cubría la cabeza. Estaba acompañado de un cántaro globular llano, con huellas de alisado tosco, de cuerpo ovoide y cuello corto con borde reforzado hacia el exterior; la base es estrecha (Fig. 19). En los alrededores se observó cerámica llana y decorada de estilo Puerto Viejo.

El segundo conjunto corresponde a otro contex to funerario hallado en los predios del Club Sol y Mar, que fue recuperado hace algunos años no contándose con el registro del contexto; sin embargo, todas las vasijas fueron retiradas y analizadas (Fig. 20). Destaca un cántaro cara gollete correspondiente al Estilo Puerto Viejo; al igual que figurinas y cántaros llanos. Algunas de las vasijas corresponden al Estilo Puerto Viejo mientras que otras piezas como los cántaros en miniatura han sido reportados en Cañete por Kroeber (1937) y por Julio C. Tello, de acuerdo a la cerámica tardía que recolectó en el sitio de Cerro del Oro.

Estas vasijas cara-gollete son comunes entre Chilca, Mala y Asia. Algunas piezas han sido halladas en Pachacamac y otras en Armatambo, siendo denominadas "de estilo Ychsma". Es importante mencionar, sin embargo, que la mayor distribución de estas vasijas corresponde a los valles precitados, por lo cual consideramos que debe tomarse en cuenta la posibilidad de que se trata de vasijas confeccionadas entre Chilca y Asia.

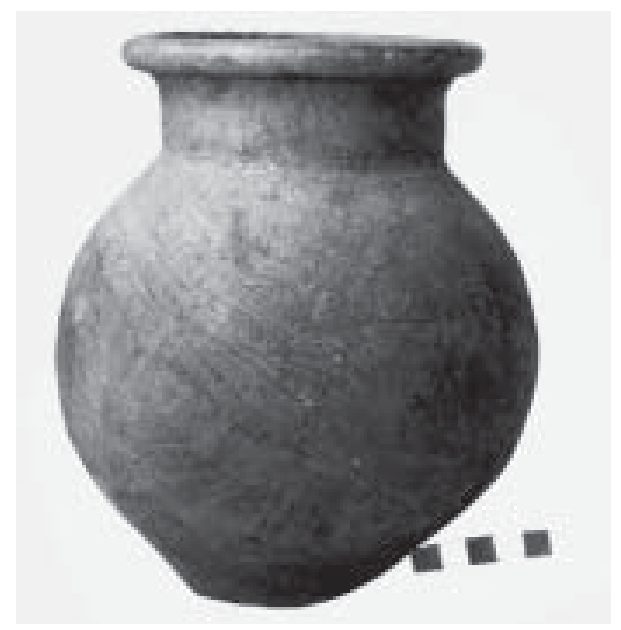

Fig. 19 - Cántaro llano procedente del litoral de Asia, sector Playa Bonita (Horizonte Tardío). 


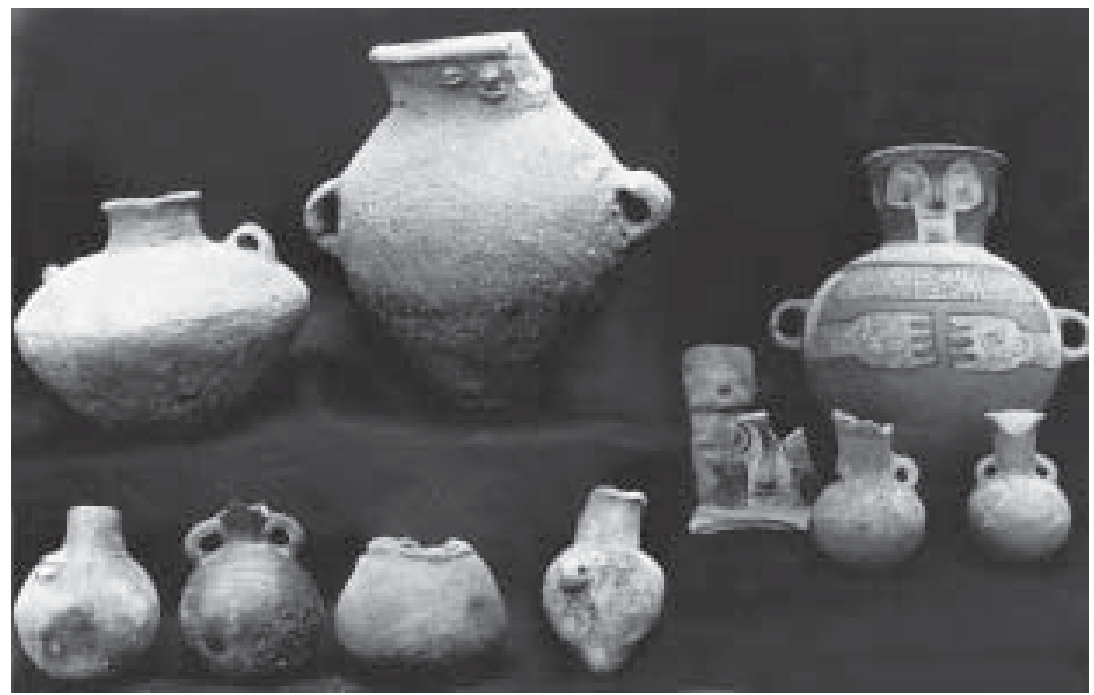

Fig. 20 - Conjunto de vasijas asociadas a contexto funerario múltiple procedentes del litoral de Asia (Horizonte Tardío).

Efectivamente los cántaros de tipo cara-gollete de cuello expandido y representando a un personaje con pintura facial representa al denominado estilo Puerto Viejo descrito por Bonavia. Su presencia en contextos funerarios frente al litoral nos confirma la fuerte relación entre los valles de Mala y Chilca y la costa central. Del mismo modo, si bien de acuerdo a la etnohistoria cada uno de estos valles representaba una unidad política, los materiales culturales tales como la cerámica se desplazaban y distribuían entre ellos, conformando una unidad cultural. Estos cántaros cara-gollete son abundantes en los basurales y cementerios de los sitios tardíos de los valles de Mala y Chilca; hacia la costa central su número es menor y al parecer se restringe a contextos funerarios. Es probable que su origen se encuentre entre Chilca, Mala y Asia, y se trate de piezas importadas hacia los valles del Rímac y Lurín.

\section{HOYAS DE CULTIVO}

Una serie de hoyas de cultivo o "chacras hundidas" (wachaques) se sitúan en el extremo norte del valle de Asia, a escasos metros del litoral. Estos sistemas de cultivo son similares a las existentes en el valle bajo de Chilca y en Pisco. Su cronología se inicia en el periodo Intermedio Tardío y llega hasta el Horizonte Tardío, conforme indica la cerámica hallada en la superficie.

\section{LOS TEJIDOS}

La ausencia de trabajos de excavación en los sitios tardíos del valle ha imposibilitado por el momento contar con materiales de estudio. Julio C. Tello recuperó un contexto de ofrenda en Huaca Malena (Tello, 2000: 157-166) que incluía objetos de metal así como una bolsa cuadrangular de estilo Inca. En la colección Tello procedente 
de Huaca Malena y depositada en el Museo Nacional de Arqueología Antropología e Historia del Perú, existe un tapiz Inca (Fig. 21), asimismo dos fajas de telar proceden del sitio Corralón, una bolsa Inca conteniendo un tocado de plumas procedente de Sarapampa y un quipu Inca procedente del sitio denominado Quisque 2 obran en custodia del Museo Huaca Malena. Las fajas recuerdan al material procedente del cementerio Inca de las mujeres sacrificadas en Pachacamac.

\section{LA OCUPACIÓN EN LAS LOMAS}

Es importante mencionar la importancia de las lomas en la vida desarrollada en el valle de Asia, espacio en el cual Frédéric Engel reportó una serie de asentamientos tempranos y líneas o geoglifos con cronología indeterminada. Igualmente existe una serie de asentamientos sin cronología definida debido a la ausencia de material cerámico. Recientemente, hemos podido observar fragmentos de cerámica cara-gollete de estilo Puerto Viejo en la loma Casablanca.

\section{APRECIACIONES FINALES}

El valle de Asia jugó un rol de importancia durante el Horizonte Medio; los contextos funerarios de Huaca Malena así como los finos textiles que los acompañan indican una fuerte relación con Wari, Pachacamac, la costa central y la costa norte.

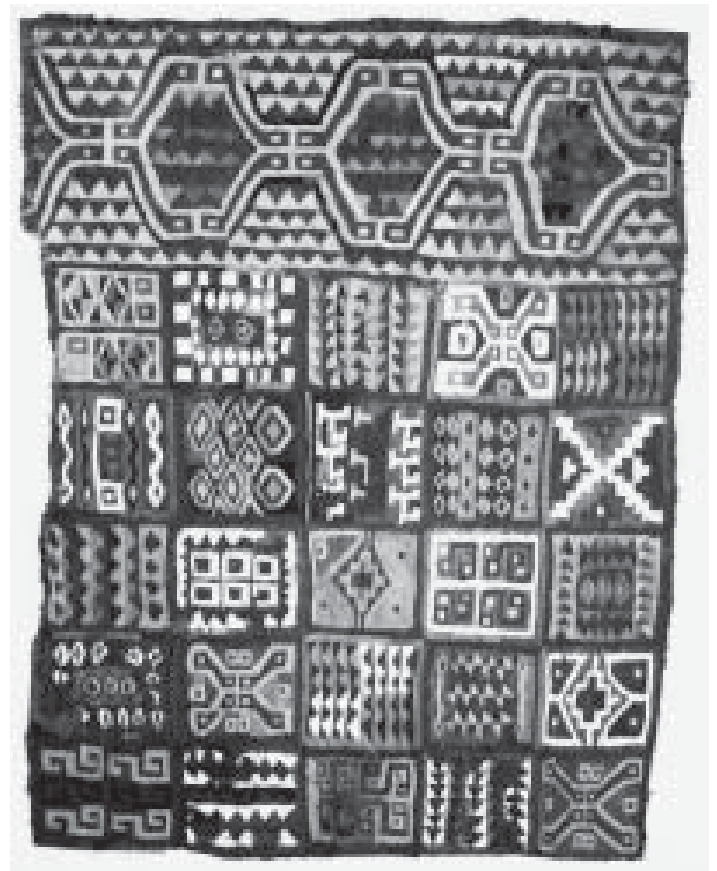

Fig. 21 - Tejido Inca en técnica tapiz excéntrico procedente de Huaca Malena (Colección MNAAHP). 
Es indudable que el valle de Asia compartió rasgos de su cerámica, arquitectura y textiles con los vecinos valles de Mala y Cañete, aunque el valle bajo de Cañete habría estado más fuertemente relacionado a Chincha, cuya relación probablemente se incrementó durante el periodo Inca.

Pachacamac como santuario debió de ejercer una fuerte influencia en las poblaciones del valle de Asia. Las excavaciones de Max Uhle en ese importante sitio mostraron contextos funerarios de similares características así como tejidos que comparten rasgos con los procedentes de Huaca Malena.

La cerámica conformada por cántaros, ollas y botellas llanas con pintura blanca aplicada de manera descuidada, que tipifica los contextos del periodo Intermedio Tardío de los valles del Rímac y Lurín, no son comunes en Asia. La arquitectura de piedra y barro comparte algunos rasgos, sin embargo, el planeamiento de los sitios tardíos entre la costa de Lima y Asia son diferentes. Los datos esbozados indican la necesidad de conocer mucho más la costa sur central para poder entender mejor la costa central.

Durante el periodo Intermedio Tardío el valle de Asia estuvo dominado por el grupo denominado Coayllo; de acuerdo a la cantidad de sitios arqueológicos, el centro más importante debió estar ubicado en el valle medio, área de mayor producción agrícola. El valle alto estaba dominado por los yauyos, quienes ocupaban las cabeceras de los valles de Mala, Asia y Cañete.

Si bien la etnohistoria reconoce grupos independientes tales como los chilca, mala, coayllo y los guarco y runahuanac en los valles de Chilca, Mala, Asia y Cañete respectivamente, resulta interesante la relación cultural estrecha que existe entre estos valles si comparamos la cerámica, los textiles y la arquitectura. Adicionalmente, en el valle bajo de Cañete hemos observado la presencia de cerámica Chincha en el sitio de Cerro del Oro.

Documentos del siglo XVII indican la existencia del Tambo de Asia, desde donde partía un camino que subía por el valle hacia la sierra central. Se indica que uno de los grandes problemas de ese entonces era la falta de agua y la aridez del valle. En el sitio Paredones existen evidencias de arquitectura colonial y de cerámica vidriada del periodo colonial. En Capilla de Asia, durante la construcción de la municipalidad, se reportó cerámica colonial temprana. El pueblo de Coayllo tiene origen colonial aunque no se descartan ocupaciones prehispánicas debajo de este. La iglesia de Coayllo fue construida en el siglo XVII-XVIII. En Piedra Estrella existen evidencias coloniales y en Uquira, Antonio Coello ha reportado la presencia de grafitis coloniales. Finalmente en Pueblo Viejo de Omas se constituyó la primera reducción colonial formada al parecer sobre parte del asentamiento Inca de la zona. 


\section{Referencias Citadas}

ANGELES FALCÓN, R., 2003 - Arqueología del valle de Asia. Cuadernos del Patrimonio Cultural, 1: 28 p.; Lima: Museo Municipal Huaca Malena.

ANGELES FALCÓN, R. \& POZZI-ESCOT, D., 2000 - Excavaciones en Huaca Malena, valle de Asia: Arqueológicas, 24: 63-75; Lima: Museo Nacional de Arqueología Antropología e Historia del Perú - Instituto Nacional de Cultura.

ANGELES FALCÓN, R. \& POZZI-ESCOT, D., 2002 - Textiles del Horizonte Medio, las evidencias de Huaca Malena - Coloquio Wari -Tiahuanaco, modelos vs evidencias: Boletín de Arqueología, 4: 401-424; Lima: Pontificia Universidad Católica del Perú. Actas y Trabajos del II Congreso Nacional de Historia del Perú ( Lima 2-9 de Agosto de 1958).

BONAVIA, D., 1959-Cerámica de Puerto Viejo - Chilca. Época prehispánicas, Vol. I: 137-168; Lima: Centro de Estudios Militares del Perú.

COELLO, A., 1998 - La Ocupación Inca en el Valle de Asia, Perú. Tawantinsuyu: An International Journal of Inca Studies, 5: 44-52; Canberra: Australian National University.

CONKLIN, W., 1978 - Estructura de los tejidos Moche. In: Tecnología Andina (R. Ravines, comp.): 299-332; Lima: Instituto de Estudios Peruanos.

ENGEL, F., 1963 - A preceramic settlement on the Central Coast of Peru; Asia, unit 1. Transactions of the American Philosophical Society, 53 (3), 139 p.; Philadelphia: The American Philosophical Society.

ENGEL, F., 1966-Geografía humana prehistórica y agricultura precolombinas de la quebrada de Chilca I, 114 p.; Lima: Universidad Agraria La Molina, UNALM.

ENGEL, F., 1987 - De las Begonias al Maíz. Vida y producción en el antiguo Peru, 255 p.; Lima: Universidad Agraria La Molina, Centro de Investigaciones de Zonas Aridas (CIZA).

ESTETE, M. de, 1968 - Noticia del Perú. In: Biblioteca peruana. El Perú a través de los siglos, t. I: 347-402; Lima: Editores técnicos asociados, ETA.

FELTHAM, J., 2000 - Textiles de la Pirámide con Rampa No 3. In: Actas de la II Jornadas Internacionales sobre Textiles Precolombinos (Victoria Solanilla, ed.): 95-114; España: Universitat Autónoma de Barcelona, Departament d,Art - Institut Catala de Cooperacio Iberoamericana.

GABE, C., 2000 - Investigaciones arqueológicas en el cerro Salazar, Mala. In: Serie de investigaciones CEAMA 1, 64 p. Lima.

KAULICKE, P., 1997 - Contextos funerarios de Ancón, esbozo de una síntesis analítica, 123 p.; Lima: Pontificia Universidad Católica del Perú, Fondo Editorial.

KAULICKE, P., 2000 - La sombra de Pachacamac, Huari en la costa central. Boletín de Arqueología, 4: 313-358; Lima: Pontificia Universidad Católica del Perú.

KROEBER, A., 1937 - Archaeological Explorations in Peru. Part IV Cañete Valley. First Marshall Field Archaeological Expeditions to Peru. Anthropology Memoirs, 2 (4): 221273; Chicago: Fields Museum of Natural History.

MENZEL, D., 1968 - La Cultura Huari, 223 p.; Lima: Compañía de Seguros y Reaseguros Peruano Suiza. Colección Las grandes civilizaciones del Antiguo Perú, 6.

OAKLAND, A. \& FERNÁNDEZ, A., 2000 - Los tejidos Huari y Tiwanaku: comparaciones y contextos. Boletín de Arqueología, 4: 119-130; Lima: Pontificia Universidad Católica del Perú.

PRUMERS, K., 2002 - El Castillo de Huarmey: una plataforma funeraria del Horizonte Medio. Boletín de Arqueología, 4: 289-312; Lima: Pontificia Universidad Católica del Perú.

REISS, W. \& STÜBEL, A., 1880-1887 - The necropolis of Ancon in Peru, a contribution to our knowledge of the culture and industries of the empire of the Incas, being the results of excavations made on the spot (Translate by A. H. Keane), 3 vols; Berlín. 
RUALES, M., 2000 - Investigaciones en Cerro del Oro, valle de Cañete. Boletín de Arqueología, 4: 359-399; Lima: Pontificia Universidad Católica del Perú.

ROSTWOROWSKI, M., 1980 - Guarco y Lunahuaná. Dos señoríos Prehispánicos de la costa sur-central del Perú. Revista del Museo Nacional, t. XLIV: 153-214; Lima.

ROWE, A. P., 1979 - Seriation on Ica Style Garment Type (A. P. Rowe, E. P. Benson, A. L. Shaffer, eds.): 185-218; Washington DC: The Textile Museum. The Junius B. Bird Pre Columbian Textile Conference.

STUMER, L., 1971 - Informe preliminar sobre el recorrido del valle de Cañete. Arqueología y Sociedad, 5: 23-35; Lima: Museo de Arqueología y Etnología de la Universidad Nacional Mayor de San Marcos.

TELLO, J. C., 2000 - Arqueología del Valle de Asia: Huaca Malena, 189 p.; Lima: Museo de Arqueología y Antropología Universidad Nacional Mayor de San Marcos. Cuadernos de investigación del Archivo Tello No 2 .

UHLE, M., 1903 - Pachacamac, Report of the William Pepper, M. D. LL. D. Peruvian Expedition of 1896, 104 p.; Philadelphia: Departament of Archaeology, University of Pennsylvania.

VANSTAN, I., 1967 -Textiles from beneath the temple of Pachacamac, Peru: a part of the Uhle collection of the University of Pennsylvania, 91 p.; Philadelphia: University of Pennsylvania, The university museum. 